\title{
Polyploidy and Meiosis in Flowering Shoots Infected with Insect Galls
}

\author{
Helen P. Ramsay \\ School of Botany, University of New South Wales, Kensington, 2033, \\ N.S.W., Australia
}

Received January 16, 1980

The prevalence of insect galls is a common feature of Persoonia falcata $\mathrm{R}$. Br. (now referred to Pycnonia Johnson and Briggs 1975) near Mareeba in North Queensland but galls do not occur on other species of Proteaceae e.g. Xylomelum, Grevillea, Hakea in the same area (G. Tracey pers. comm.). Gall formation on leaves or young branches, inflorescences or fruit resulting from insect attack occur frequently in many Australian native plant species particularly in the genera Eucalyptus and Acacia. Mani (1964) states that more than half the known galls from Australia are found on taxa in the family Myrtaceae. The Proteaceae are listed by Karny (1926) as having the highest gall index in the Monochlamydeae, the Angiosperm group which has the optimum for gall adaptations.

Zweigelt believes that the formation of the gall is the result of a gradual process of mutual adaptation between the gall-inducing organism and the gallbearing plant, and indeed most gall-forming organisms are host specific. A wide variety of insect groups include gall-forming species e.g. Diptera, Hymenoptera, Coleoptera, Homoptera (particularly Aphidae, Coccoidea), Heteroptera (Mani 1964).

Galls occur in many regions of the plant from root tip to growing apex both on vegetative and reproductive organs. Leaves are most frequently attacked accounting for about $65 \%$ of galls, $19 \%$ are found on stems or branches but only $4 \%$ occur in flowers (Mani 1964).

Information regarding the effect of gall damage on mitotic cells is well documented. Polyploidy, nuclear gigantism, multinucleate conditions, excess of free amino acids or other stituations in one cell induced by the cecidogenetic agent influence neighbouring cells within a certain distance. This may result in a new activated region and a new gradient field for cell development and differentiation. Secretions from the insect may give rise to the formation of certain substances in the cytoplasm of the plant cell favouring polypolidy and repeated cell divisions. The secretion or its reaction on the cell will be maximum at the point of attack and its effects diminish as distance from this point increases. The most actively dividing cells are found immediately around the gall organism and the frequency falls in cells some distance away, until at about three times the radial distance from the larval cavity, it ceases (Mani 1964).

Gall formation originates in the epidermis, cortex or vascular bundle tissue depending on the point of attack by the cecidozoan. Cell proliferation leads to both 
hyperplasy and hypertrophy of the tissues resulting in the gall. The structure of the gall is so characteristic in many cases that the attacking organism is able to be readily identified. Mani gives a comprehensive survey of knowledge on the histogenesis, cytology, development, frequency and ecological significance of galls.

\section{Results}

In this study polyploid spore mother cells undergoing meiosis were detected in gall infected flowering shoots of Persoonia falcata. Specimens were kindly supplied by Mr. J. G. Tracey and Dr. P. Macnicol during 1962 and 1963 whilst they were stationed with CSIRO at the Tobacco Research Institute in Mareeba, North Queensland.

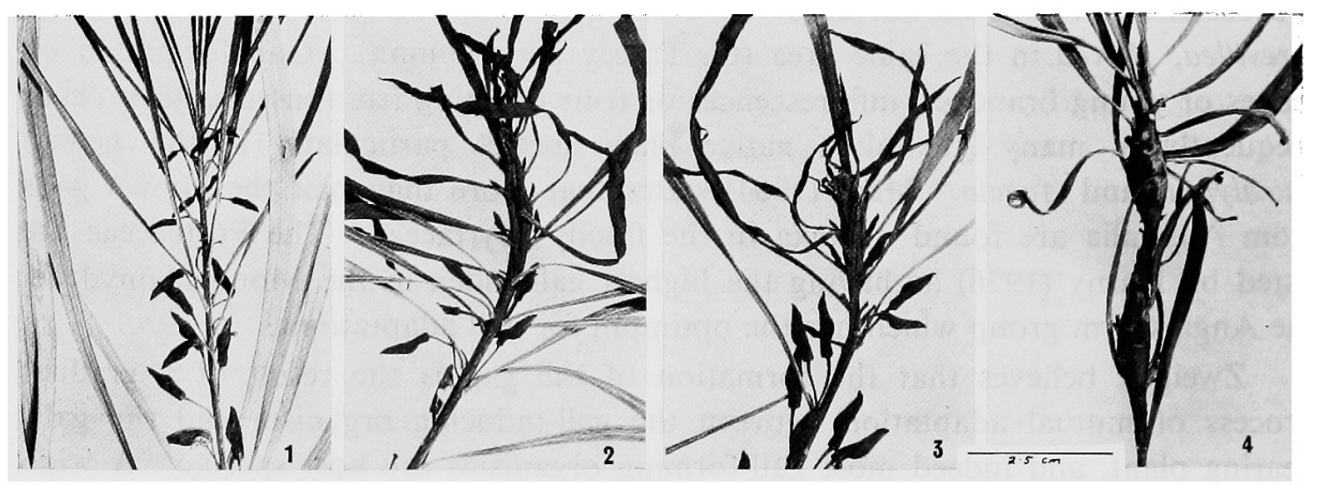

Figs. 1-4. Persoonia falcata-flowering shoots. 1, normal flowering shoot. 2-4, infected flowering shoots showing various degrees of gall infestation.

The chromosome number, $\mathrm{n}=7$, was recorded previously for normal plants of Persoonia falcata (Ramsay 1963). In what appeared to be normal flower buds from swollen infected pedicels (Fig. 2) meiosis in anthers had abnormal first prophase and metaphase stages. Bivalents at meiosis in normal shoots are large and contracted at metaphase I (Figs. 5, 11) and behave normally at MII, AII (Figs. 6, 12.) In infected shoots (Figs. 2-4) the chromosomes were less contracted than normal (Fig. 16) and bivalent formation was rare while late prophase stages appeared to have possible multivalents (Fig. 15). Fourteen bivalents were counted in the few apparently normal metaphases (Fig. 7) and the number confirmed at anaphase I (Figs. 8, 14). The abnormal division in most cells resulted in laggards (Fig. 10) bridges (Fig. 9) and some misdivision of cells. Size of pollen mother cells appeared to be larger in polyploids. On the same shoot anthers in older flowers contained "normal" tetrads and apparently viable pollen grains. The stage in development of the shoot at which the attack took place and whether the older flowers had completed meiosis too early to be affected or were polyploid was not able to be determined. The causative agent although found to be the pupa of a moth in one gall, others being empty, could not be positively identified. 


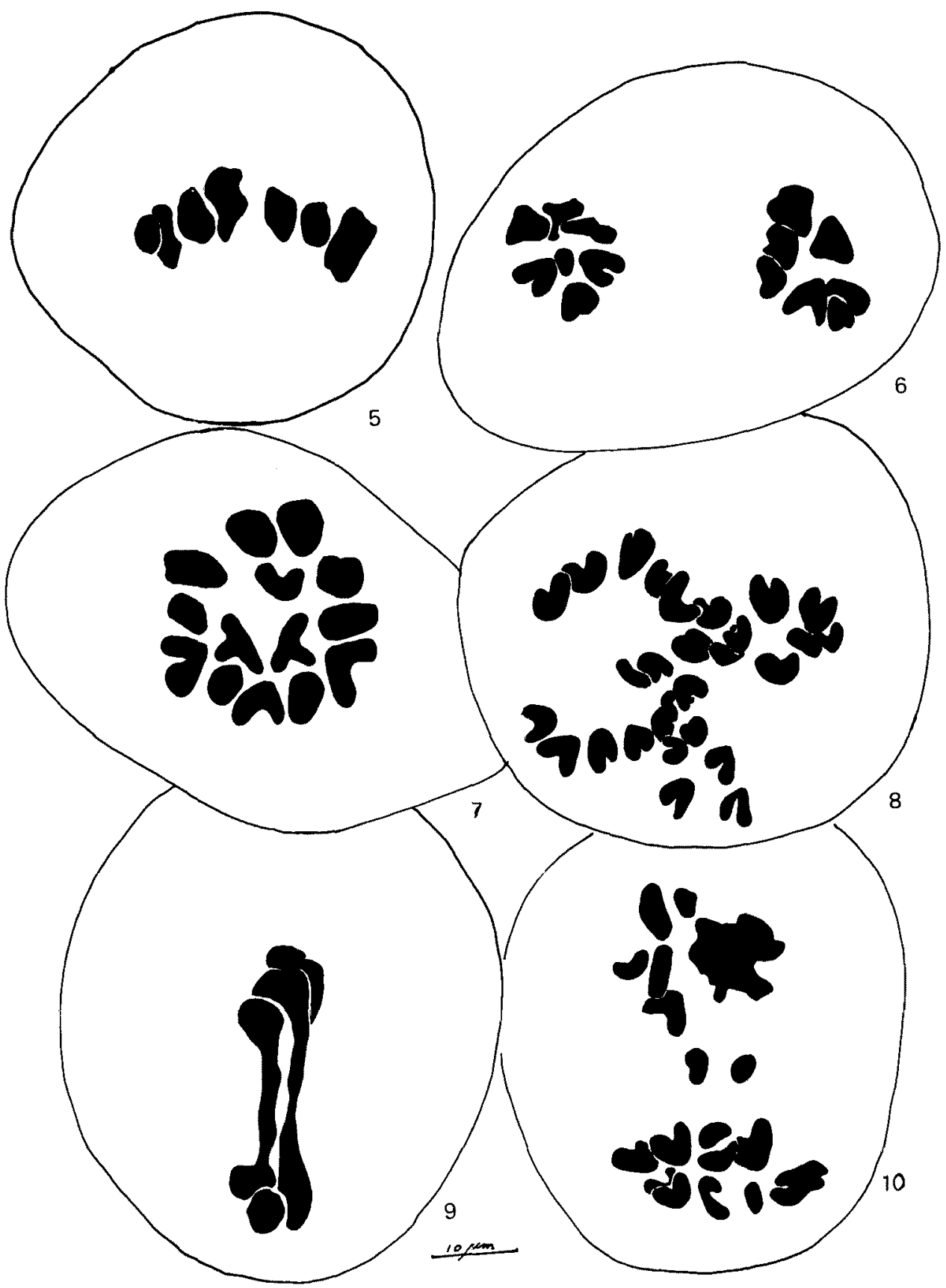

Figs. 5-10. Drawings of pollen mother cells at meiosis. 5, side view MI, normal cells with seven bivalents. 6, MII in normal PMC $\mathrm{n}=7.7, \mathrm{MI}$ showing 14 normal bivalents, from infected shoot. 8, AI showing 14 chromosomes at each end. 9-10: Abnormal divisions. 9, chromosomes clumped and forming bridges at AI. 10, laggards at AI. 


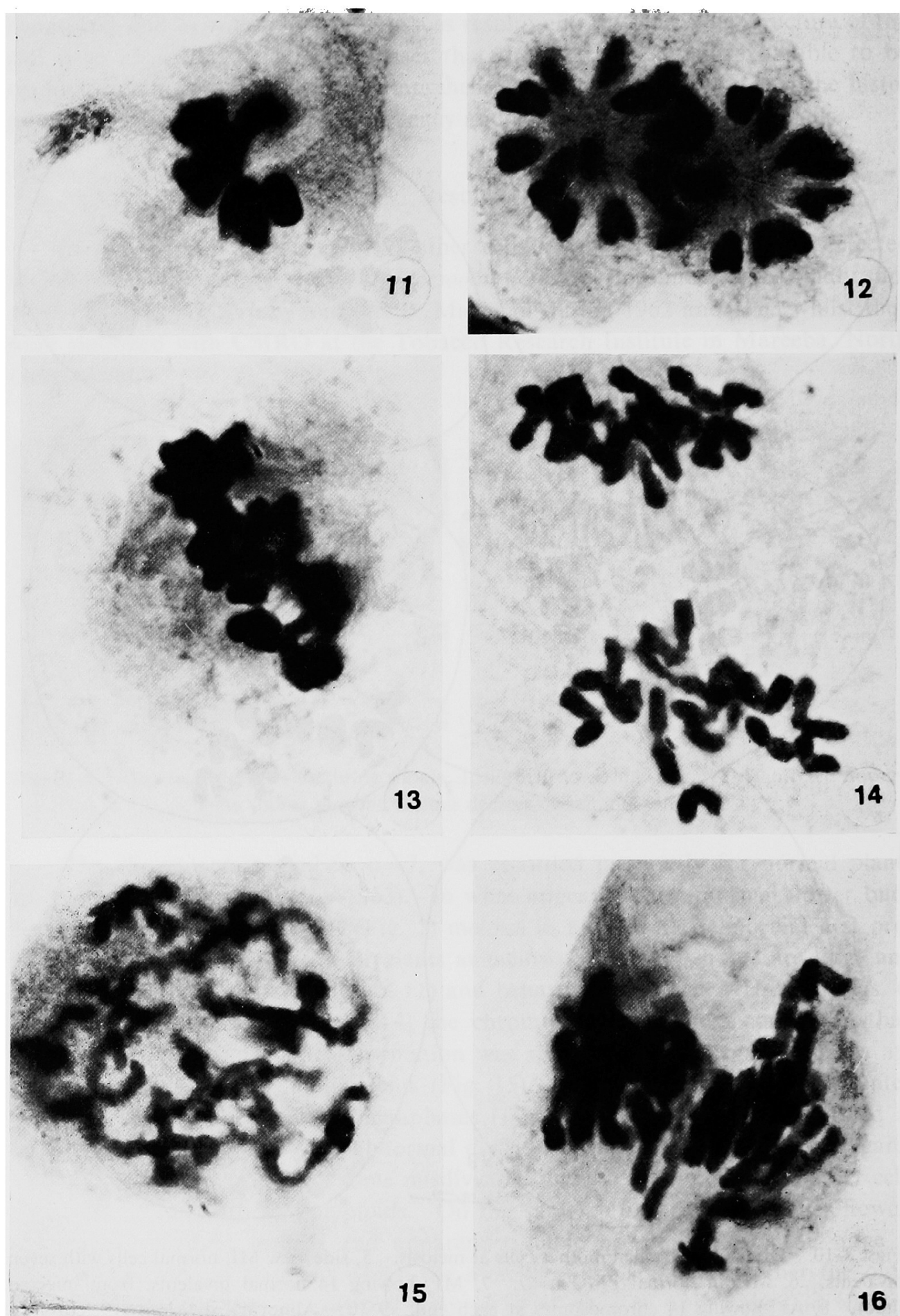

Figs. 11-16. Photomicrographs of meiosis in PMC. $\times 1300$. 11, normal MI showing 7 bivalents. 12, normal MII polar view (late) with chromatids beginning to separate. 13, side view MI in abnormal cell-bivalents on metaphase plate, note increased size of cell. 


\section{Discussion}

Only a limited amount of work has been carried out on Australian gall-forming insects mainly early in the century by Frogatt $(1907,1930)$. Angiosperms bear about $98 \%$ of all known galls with $93 \%$ occurring on the Dicotyledonae. Members of some insect taxa are known to specifically infect certain regions of the plant such as floral parts, stems, leaves etc. Gall-forming insects which most commonly attack the shoot apex belong to the Diptera and Hymenoptera and both of these groups are also significant amongst those attacking flowers on flowering shoots (Mani 1964). Cell proliferation in flowers induced by insects is usually localised in the androecium and gynoecium or the perianth or both. If the cecidogenetic growth is localised e.g. in perianth, it does not prevent normal development of the androecium or gynoecium but may not favour normal opening development of the flower (Mani 1964). The type of effect on the floral parts therefore would depend on the initial point of attack by the insect and the final morphogenetic fate of cells in direct lineage from the cells at the origin of the infestation.

Cytological abnormalities and tetraploidy due to nuclear division in the absence of cell division are known to result from cecidotoxins which attack the spindle. Once a cell becomes polyploid it may proliferate rapidly producing numbers of polyploid cells. Cell proliferation is usually localised. The frequency of cell division falls with increase in distance from the origin of the attack. It would seem, therefore, that if primordial cells in the embryonic stages of flower bud differentiation were to become polyploid all future cells in their lineage would also be affected. If the initial attack was not severe, or if the floral primordial cells were some distance from the origin, then rapid cell division without hypertrophy could lead to development of apparently normal polyploid flowers or floral parts. In hypertrophy, cell division and nuclear division may progress independently of each other and nuclear division may be inhibited even if the growth of the cell is not affected appreciably, so that the histogenetic and morphogenetic processes operate independently rather than in sequence (Mani 1964). In the present example the floral organs were not hypertrophied, the gall being below the floral parts on the pedicel.

The finding of polyploidy apparently induced by gall-forming insects in meiotic cells suggests an interesting and accidental mechanism for possible autopolyploidy. It may be a phenomenon with no permanent result as most affected buds aborted before forming fruit (Tracey pers. comm.). The possibility exists, however, that viable pollen could be produced, and assuming that meiosis in the ovule of similarly affected buds produced a diploid ovum, tetraploid fruits, which might be viable could be formed. Persoonia is a cytologically stable genus (Ramsay 1963, Johnson and Briggs 1963, 1975) and polyploids have only been recorded for one species Persoonia toru a New Zealand species $(n=14)$ (Hair and Beuzenberg 1959) which has now been placed in a separate genus Toronia (Johnson and Briggs 1975).

14, AI in polyploid cell- $n=14.15$, late prophase in polyploid cell-note diakinesis configurations irregular. 16, metaphase in which bivalents have not formed-chromosomes on metaphase plate not contracted and irregularly arranged. Note: In polyploids SMC size is larger than in diploid cells. 
Karny (1926) found that occurrence of galls was highest in younger plant orders and lowest in the most ancient groups. He concludes that "a certain definitive phylogenetic antiquity constitutes an optimum condition for resistence to production of galls so that older classes produce few galls" while younger ones are more susceptible to attack. He also found that galls occurred on younger members of older plant groups as these would be sufficiently plastic to undergo the mutual series of adaptations, with the insect, necessary for the development of galls.

The Proteaceae has the highest gall index (140.0) in the Monochlamydeae (Mani 1964). This does not agree with the taxonomist's view of the Proteaceae as a family which is considered ancient phylogenetically since "it is evident that the Proteaceae had already diverged considerably from the most primitive Angiosperms and it has no close relatives today (Zweigelt 1942, Johnson and Briggs 1975).

Johnson and Briggs (1975) further re-iterated their belief that the evidence from taxonomy, fossil data, chromosome numbers "is consistent with an early divergence from primitive stock and with some affinity with Rosales", a view also held by Thorne (1976). A. R. H. Martin (pers. comm.) believes that evidence from fossil pollen supports an ancient origin, as does Melville, based on evidence from fossil leaves and geographical distribution of the family. Melville (1975) suggests that the floral specialisations belong to a later cycle of evolutionary diversification dating back to the Cretaceous and were a re-adaptation of the reproductive structures for pollination by Hymenoptera, Lepidoptera and birds, animal phyla which were also expanding and diversifying in the Cretaceous. It is possible, however, that species or genera within this family which are considered recent from an evolutionary standpoint, i.e. those still plastic, could show susceptibility to insect attack not present in older genera or species.

This study confirms that polyploidy may be induced by insect attack on flowering stems, that meiosis can occur in flowers produced after polyploidy, and suggests that it is conceivable that such a change in chromosome number might result in viable fruits. Although polyploidy induced by gall insects in mitotic cells is well documented, no reports of interference with meiosis seem to have been recorded. Since there has been such a close evolutionary interrelationship between plant and insects in the Angiosperms this finding poses the question-

"From the evolutionary viewpoint can the close ecological relationship between gall-forming insects and plants have played any role in the origin of polyploids in some plant taxa".

\section{Abstract}

The occurrence of polyploid cells in developing flowers undergoing meiosis following gall attack on the flowering stems is discussed. Tetraploid pollen mother cells in some flowers underwent normal meiotic division producing apparently normal tetrads. In others meiosis showed many abnormalities. Although much has been documented on effects of galls on mitotic cells no information has been available previously on effects on meiosis and its possible significance. 


\section{Acknowledgements}

I wish to thank Dr. J. G. Tracey, Dr. P. Macnicol for supplying specimens and several members of staff from Entomology Section of the Department of Agriculture, N.S.W. for their assistance in studying galls and supplying information on reference material.

\section{References}

Froggatt, W. W. 1970. Australian insect galls. Austr. Nat. 1 (7): 79-83.

- 1930. Australian insect galls. Part II. Proc. Linn. Soc. N.S.W. 55 (4) : 468-474.

Hair, J. B. and Beuzenberg, E. J. 1959 . Contributions to a chromosome atlas of New Zealand flora 2. N. Z. J. Sc. 2: 148-56.

Johnson, L. A. S. and Briggs, B. G. 1975. On the Proteaceae-The evolution and classification of a Southern Family. Bot. J. Linn. Soc. 70: 83-182.

Karny, H. 1926. Phylogenetic considerations, in Leeuwen, W. and Leeuwen-Reinjnvaan, J. The Zoocecidia of the Netherlands East-Indies. Batavia. 37-47.

Mani, M. S. 1964. The Ecology of Plant Galls. JUNK. The Hague.

Melville, R. 1975. The Distribution of Australian relict plants and its bearing on angiosperm evolution. Bot. J. Linn. Soc. 71: 67-88.

Ramsay, H. P. 1963. Chromosome numbers in the Proteaceac. Aust. J. Bot. 11 (1): 1-20.

Thorne, R. F. 1976. A phylogenetic classification of the Angiospermae. Evolutionary Biology. 9: 35-106. (eds. Hecht, Steere \& Wallace).

Zweigelt, F. 1942. Beiträge zur Kenntnis der Blattlausgallen. Biol. Gen. 16: (4) 554-572. 